\title{
Study on the Interfacial Transition Zones of Recycled Aggregate Concrete
}

\author{
A. Sahu*, T. Dey and S. Chakraborty \\ Department of Civil Engineering, Indian School of Mines, Dhanbad - 826004, Jharkhand; asdhn27@gmail.com, \\ tanish.be@gmail.com,sukanta069@gmail.com
}

\begin{abstract}
Background/Objectives: The objective of the present paper is to study the effect of admixtures and the mixing approach on the Interfacial Transition Zone (ITZ) of Recycled Aggregate Concrete (RAC). Methods/Statistical analysis: The micro structure of RAC is generally analyzed by the Vickers micro-hardness test, Atomic-Force Microscopy (AFM), Nanoindentation and scanning electron microscope (SEM). The various mixing approaches were presented for partially and fully replacement of recycled aggregate (RA) which basically enhanced the properties of RA. It is also observed that the use of fly ash and silica fume improve the properties of ITZ. Findings: This paper presents a review of the studies on the micro structure and mixing approach of RAC elements and Structures. The behavior of RAC has been studied since last 45 years. In this paper micro structure of RAC and mixing approaches conducted by many researchers are critically studied for the enhancement of strength and durability of RAC. The findings and recommendations derived from the earlier research may be helpful for the design engineers and professionals for proper design of structural components using RAC. This will also help in popularizing the use of recycled concrete aggregate in Civil Engineering field. Applications/Improvements: To achieve sustainable issue in construction area the use of waste concrete as RAC is an important focus for construction industries and for the safe guard of the natural environment.
\end{abstract}

Keywords: ITZ, Mixing Approach, RAC

\section{Introduction}

The RAC is widely used in all over the world. Recycling of concrete is necessary from the viewpoint of environmental preservation, shortage of land for waste disposal and the effective utilization of resources. It is not only make the concrete economy but also gives higher volume stability, better durability and higher strength than the hydrated cement paste. RCA is a sustainable building material and it reduces the need for virgin aggregates. Recent research in concrete technology reports shows that concrete with RCA performs similarly to concrete with natural aggregate. For using RCA as a construction material, all the essential properties of RCA must be equivalent to the properties of natural aggregate. The main reason of possible reduction of different essential properties of RAC is because RAC has two inter-facial transition zones (ITZs), one is between the RCA and new mortar matrix (new ITZ), and the other is between the RCA and the old mortar attached (old ITZ). The old mortar of the RCA forms the weak link in RAC, which is composed of many porosity and cracks. Proper RAC mix design is recommended by researchers in the past to enhance the properties of ITZs. The literature reveals that the addition of fly ash to the RAC enhances some of its properties. In the present paper a brief review of the existing studies on the micro structure and mixing approach of RAC elements and Structures is presented. The review of the literatures is carried out in two sections: Interfacial Transition Zone and Mixing Approach.

\subsection{Interfacial Transition Zone (ITZ)}

ITZ is an important stage that affects the mechanical and durability properties of RAC. The author examined the

${ }^{*}$ Author for correspondence 
influence of RA on ITZ. ITZ is the effective part of RAC that affects the strength and durability of concrete. Vickers micro-hardness test was carried out to find the characteristics of ITZ. They concluded that the characteristic of ITZ is influence by the quality of mortar surrounding the recycled aggregate ${ }^{1}$. The effect of microstructure of ITZ on compressive strength of RAC was studied by using silica fume. The microstructure of RAC was observed by SEM and the porosity and pore size distribution of RA was seen by MIP. They concluded that the high perform RAC has dense interfacial transition zone than normal strength concrete it is due to the higher porosity and absorption capacity of $\mathrm{RA}^{2}$. The Two-Stage Mixing Approach (TSMA) was proposed to improve the ITZ around the RA. This approach basically fills up some cracks and pores which make the concrete dense and enhanced the strength of RAC ${ }^{\underline{3}}$. The TSMA was again modified and named as TSMAproportional-1 (TSMAp1) and TSMAproportional2 (TSMAp2) to improve the properties of ITZ and quality of RAC. The cement slurry was used during premix procedure in TSMAp1 which covered the surface of RA rather than NMA. Whereas cement with low water cement ratio was used in TSMAp2 which fills the pores and cracks of RA than TSMAp1 and NMA at first stage of mixing, hence weak link of ITZ was improved by this method ${ }^{4}$. The TSMA used for $0 \%$ to $100 \%$ substitution of RA and compared with NMA. Better ITZ properties were observed by using TSMA than NMA ${ }^{5}$. The TSMA by adding silica fume and silica fume + cement was proposed, named as TSMAs and TSMAsc respectively. This approach was used for $5 \%$ to $30 \%$ of RA. Good ITZ was observed in this procedure ${ }^{6}$. The effect of different mixing approaches on the properties of ITZ in RAC was investigated. Nano-indentation and Scanning Electron Microscopy (SEM) were used to know the Nano mechanical properties and microstructures of ITZs (i.e. old and new ITZ) respectively. Figure 1a shows that the indentation modulus increases when distance increases from the aggregate surface for old ITZ. For new ITZ with TSMA, there was no indication while new ITZ with NMA modulus decreases from old paste matrix. Hence TSMA gave stronger new ITZ. Figure $1 \mathrm{~b}$ shows the probability of modulus which corresponds to porosity and $\mathrm{CH}$ phases were lesser in new ITZ with TSMA than the old and new ITZ with NMA, which improve the microstructure of new ITZ ${ }^{Z}$. The influence of mix proportion, aggregate type and hydration age on the properties of new and old ITZ was investigated by AFM, SEM and Nanoindentation. With the increase in hydration porosity and thickness of new ITZ decreases and new ITZ become stronger and denser. By Atomic Force Microscopy (AFM) it was seen that the old ITZ has higher roughness than new ITZ and also found that the both old and new ITZ region are flat in RAC. From SEM it was found that old and new ITZ has higher porosity than the paste matrix and dense zone was found near to new ITZ at old paste. And by Nanoindentation the thickness of old ITZ and new ITZ were $40-50 \mu \mathrm{m}$ and 55-65 $\mu \mathrm{m}$ respectively at 90 days but the modulus of old and new ITZ was observed $70-80 \%$ of old paste matrix and $80-90 \%$ of new paste matrix respectively. It was concluded that the indentation modulus of new ITZ in RAC (having water binder ratio of 0.42 ) was lower than new ITZ in RAC (having water cement ratio of 0.45 ) and thickness of new ITZ in RAC (having water binder ratio of 0.42 ) was greater than RAC (having water cement ratio of 0.45 ) because the RAC (having water cement ratio of 0.42 ) contain fly ash. So the thickness of new ITZ decreases when the hydration age increases and the new ITZ become denser and stronger ${ }^{8}$. The experimental investigation was done to find the influence of RA on RAC and also the influence on strength of RAC after the test. The vicker hardness test was used to get the hardness of ITZ between aggregate and mortar. In this studied the effect of old mortar on RA surface was determined. Author observed that the natural aggregate concrete (NAC) failed with the development of cracks in the ITZ between natural coarse aggregate (NCA) and cement mortar after compression and tensile test. Whereas the RAC was failed by both with the development of cracks in the ITZ between RCA and cement mortar and with the ITZ failure of aggregate itself. The RCA fell off more easily than NA from new mortar and bigger ITZ cracks was in RAC. It was also found that the micro hardness value was larger in both new ITZ and mortar zone compared to old ITZ and mortar zone respectively ${ }^{2}$. Figure 2 shows the vicker hardness test values. Lee and Choi concluded that the micro-hardness value tends to increase in old mortar zone $(120-180 \mu \mathrm{m})$ while in new ITZ $(180-210 \mu \mathrm{m})$ microhardness value was decreased. On the other hand, Otsuki has found that the micro-hardness value increases as the water-binder ratio decreases, where $\mathrm{B} 2$ represent the RA which having $\mathrm{w} / \mathrm{b}$ ratio of 0.55 and $0.40^{1.9}$. The author used the stone chips and granite chips and the properties of granite chips were studied and compared with the conventionally used aggregate material, and observed that the increases in the percentage of the granite results to increases in strength of the concrete ${ }^{13}$. 


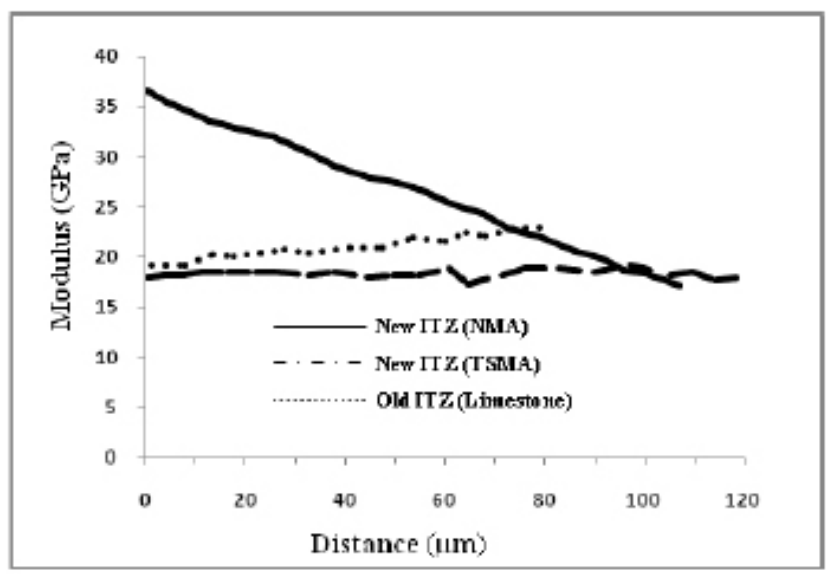

(a)

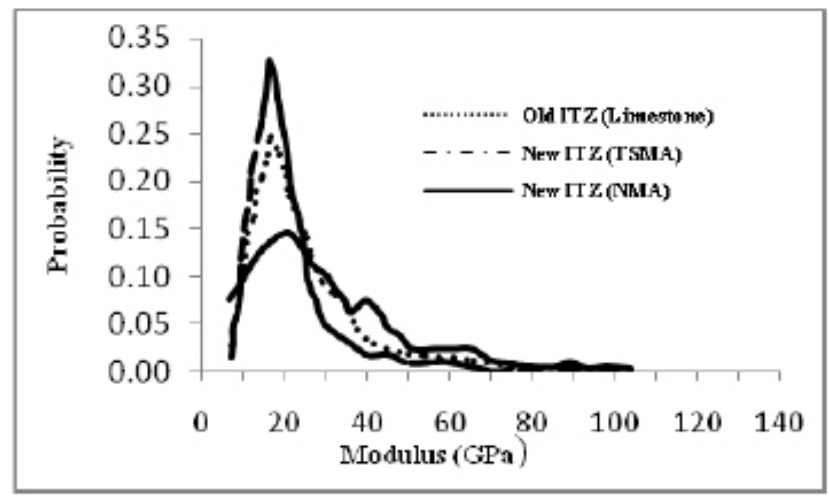

(b)

Figure 1. Nano-mechanical properties characteristics of old ITZ and new ITZ in RAC (a) Average modulus distribution of ITZs (b) Average modulus statistical analysis of ITZs.

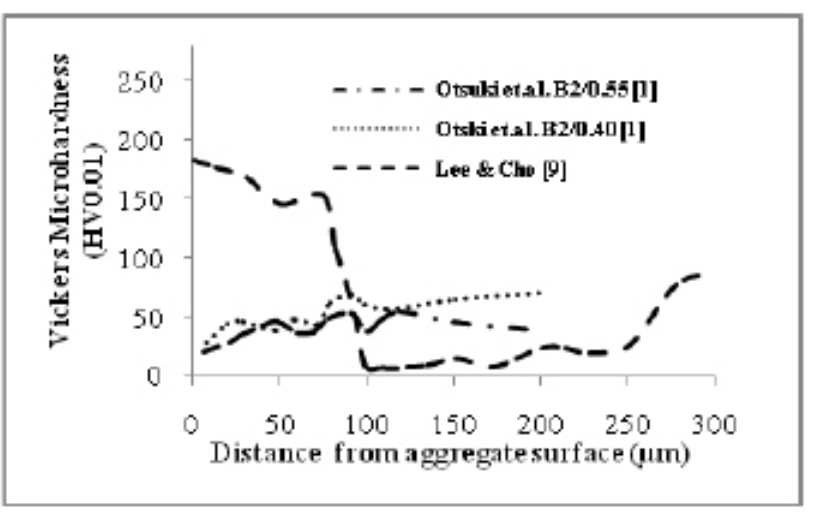

Figure 2. Vicker micro-hardness distribution at new ITZ of RAC.

\subsection{Mixing Approaches}

Figure 3 shows the Double mixing method, for $100 \%$ substitution of RA the compressive and tensile enhanced by $4.18 \%$ and $5.25 \%$ respectively by using DMM, at 28 days of curing similarly the chloride penetration and carbonation resistance also improved when compared with NMA of w/c $+0.55^{1}$. Figure 4 shows the Two Stage Mixing Approach. Tam et al. have proposed TSMA to improve the quality of RAC. At 28 days of curing the compressive strength was enhanced by $21.19 \%$ for $20 \%$ replacement of RCA 3 . Figure 5(a) and Figure 5(b) shows the mixing approach TSMA $A_{p 1}$ and TSMA $A_{p 2}$ respectively. At 28 days of curing the compressive strength was enhanced by $11.47 \%$ of $25 \%$ replacement of RCA and $19.75 \%$ of $20 \%$ replacement of RCA for the TSMA ${ }_{\mathrm{p} 1}$ and TSMA $\mathrm{T}_{\mathrm{p} 2}$ respectively. For modulus of elasticity there was no much difference observed $^{4}$. Figure 6(a) and Figure 6(b) shows the TSMA and TSMA $A_{\text {sc }}$ mixing approach respectively. At 28 days of curing, the compressive strength, flexural strength, tensile strength and static modulus of elasticity were enhanced by $19.50 \%$ (with $25 \%$ RA substitution), $20.04 \%$ (with $20 \%$ RA substitution), $16.16 \%$ (with $10 \%$ RA substitution) and $16.28 \%$ (with $30 \%$ RA substitution) respectively for TSMAs. On the other hand, for TSMAsc the compressive strength, flexural strength, tensile strength and static modulus of elasticity were enhanced by $19.73 \%$ (with 25\% RA substitution), 4.44\%(with 25\% RA substitution), $24.22 \%$ (with 5\% RA substitution) and $11.92 \%$ (with 30\% RA substitution) respectively when compared with $\mathrm{NMA}^{6}$. According to $\mathrm{Li}$ et al. the compressive strength was enhanced by $3.21 \%$ (with $100 \%$ RA substitution, at 28 days $)^{7}$. Figure 7 shows the Two Stage Mixing method ${ }^{10}$. At 28 days of curing, the compressive strength improved $20.5 \%$ ( with $75 \%$ RA substitution) when cement content was $250 \mathrm{~kg} / \mathrm{m}^{3}(\mathrm{w} / \mathrm{c}=0.60)$ and $2.3 \%$ ( with $75 \% \mathrm{RA}$ substitution) when cement content was $400 \mathrm{~kg} / \mathrm{m}^{3}(\mathrm{w} / \mathrm{c}=$ 0.45 ) whereas tensile strength enhanced by $54.6 \%$ ( with $75 \%$ RA substitution, cement content $250 \mathrm{~kg} / \mathrm{m}^{3}$ ) 13.8\%( with $75 \%$ RA substitution, cement content $400 \mathrm{~kg} / \mathrm{m}^{3}$ ) and bond strength for cement content $250 \mathrm{~kg} / \mathrm{m}^{3}$ was $13.1 \%$ ( with $75 \%$ RA substitution) and $42.9 \%$ for cement content $400 \mathrm{~kg} / \mathrm{m}^{3}$ ( with 75\% RA substitution) ${ }^{10}$. Figure 8(a) and Figure 8(b) shows the Motar Mixing Approach and Sand Envaloped Mixing Approach respectively. At 28 days of curing and $0.45 \mathrm{w} / \mathrm{c}$, the compressive strength was observed higher than MMA and TSMA when SEMA used $^{11}$. Figure 9 shows the Mixing Approach where the compressive strength of RA1CSF10 (40\% RA content) and RA2CSF10 (30\% RA content) and tensile strength of RA2CSF5 (30 \% RA content) and RA2CSF10 (30 \% RA content) were higher than NMA at 28 days of curing ${ }^{12}$. 


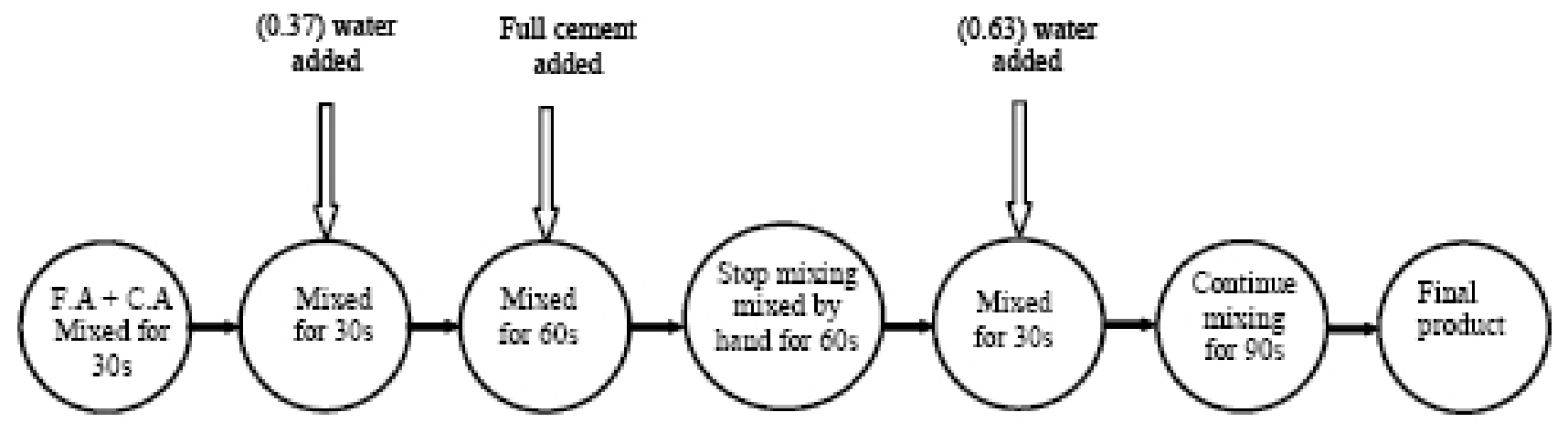

Figure 3. Double mixing method1.

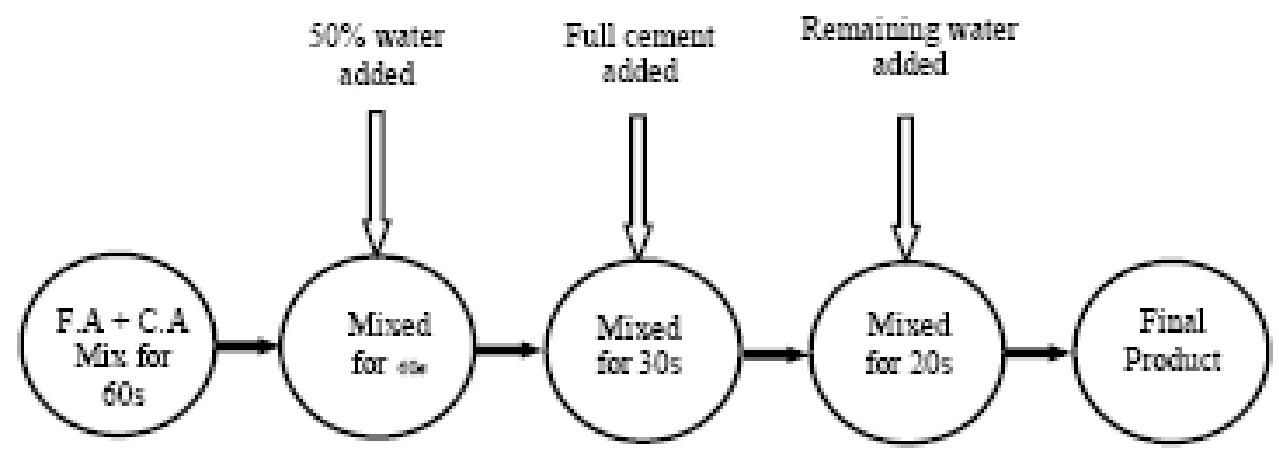

Figure 4. Two Stage Mixing Approach3.

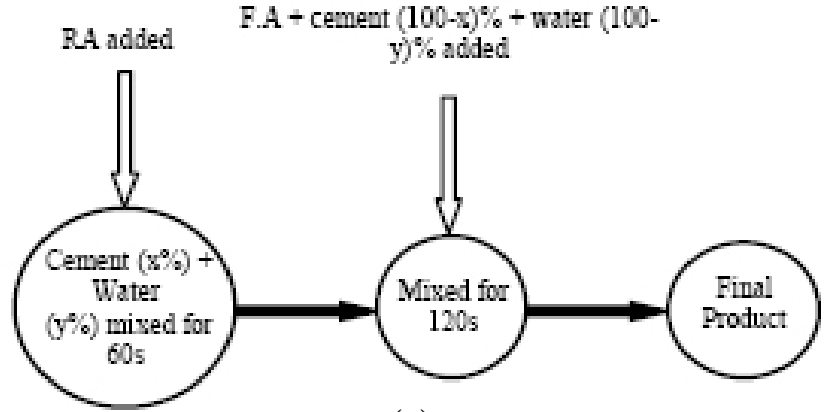

(a)

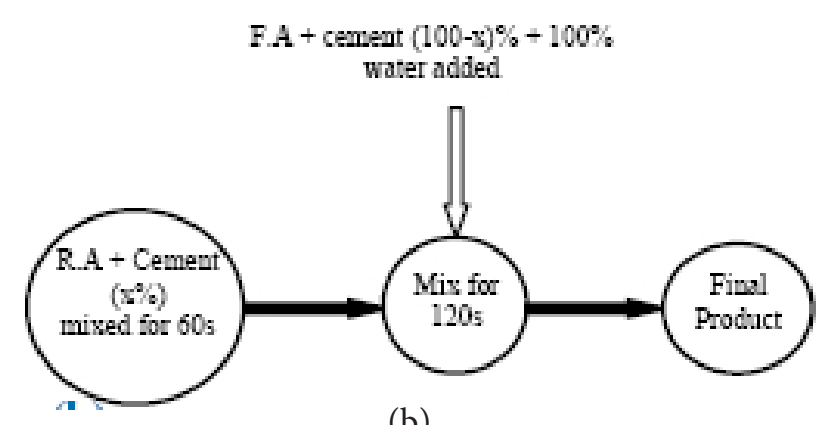

(b)

Figure 5. (a) $\mathrm{TSMA}_{\mathrm{p} 1}$ (b) $\operatorname{TSMA}_{\mathrm{p} 2}$.

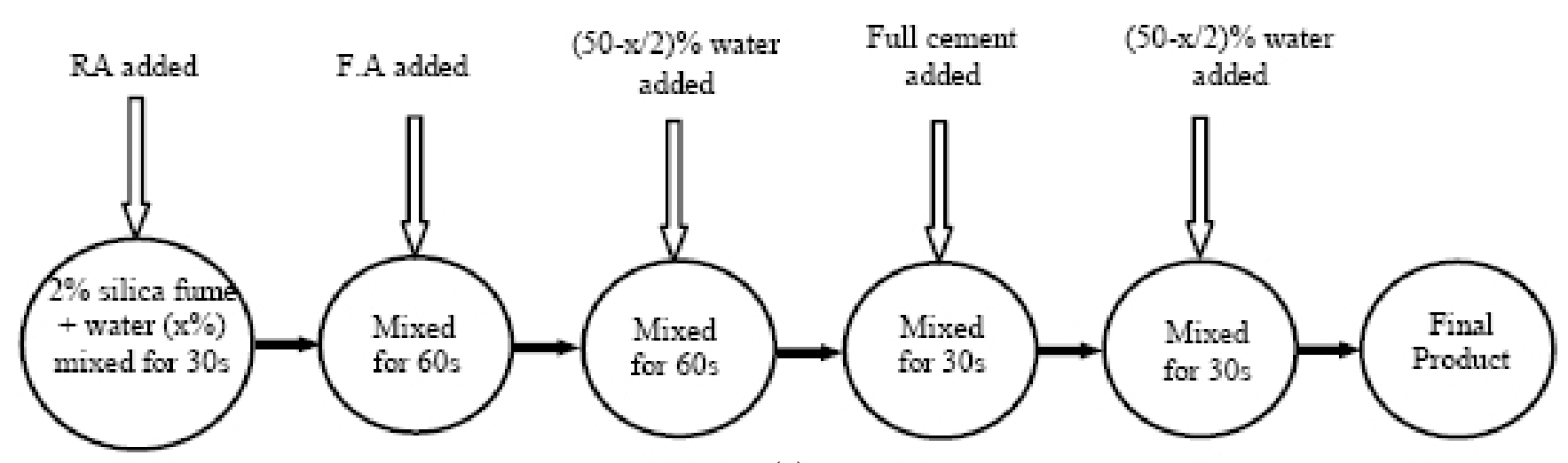

(a) 


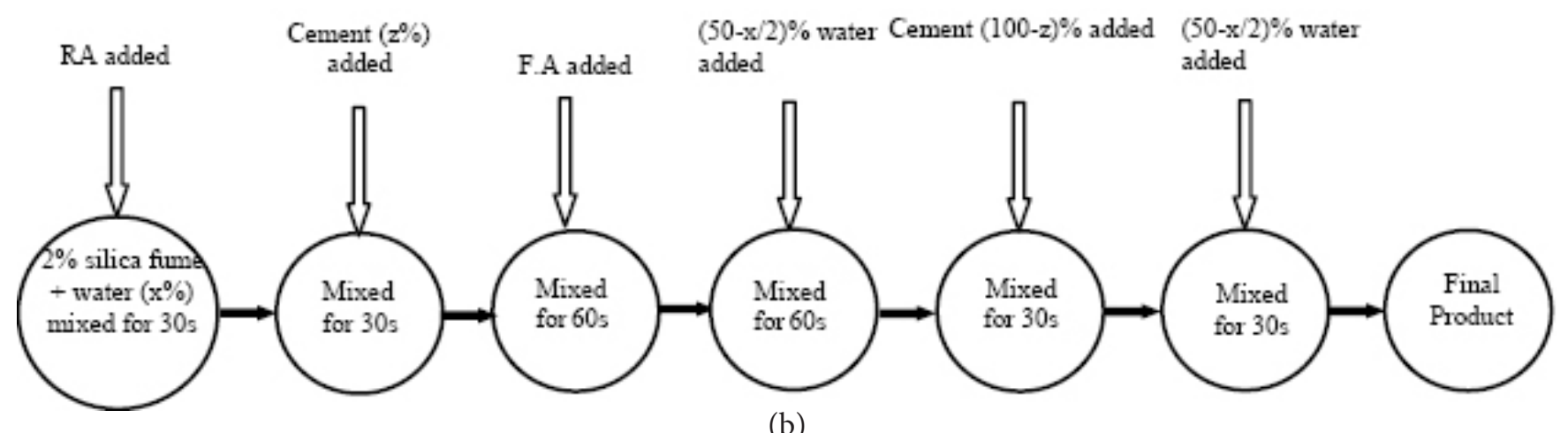

(b)

Figure 6. (a) $\operatorname{TSMA}_{\mathrm{s}} \frac{6}{(b)} \operatorname{TSMA}_{\mathrm{sc}} \frac{6}{6}$.

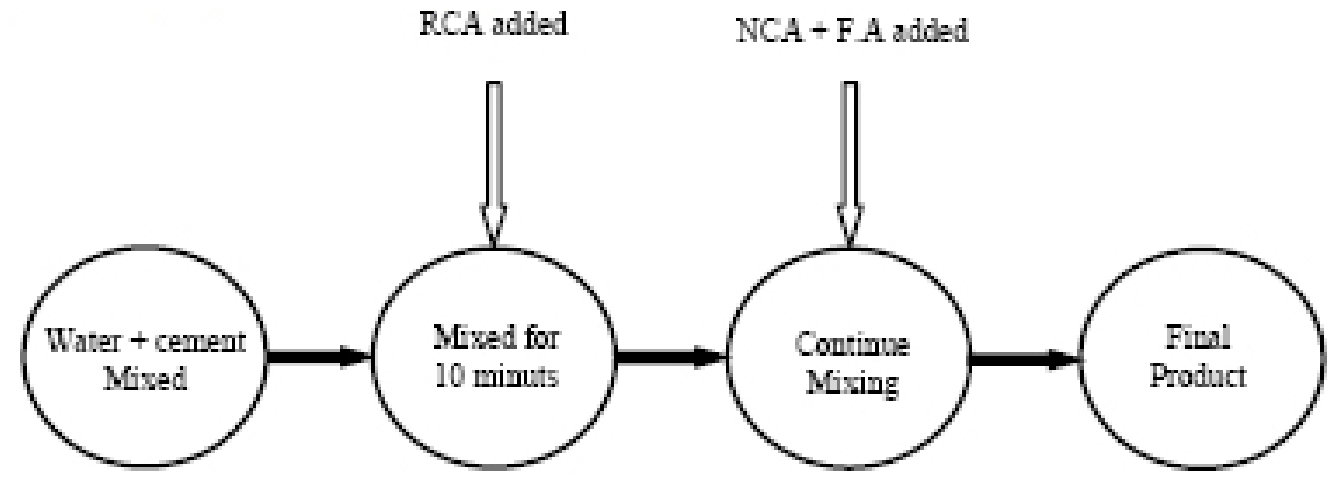

Figure 7. Two Stage Mixing method ${ }^{10}$.

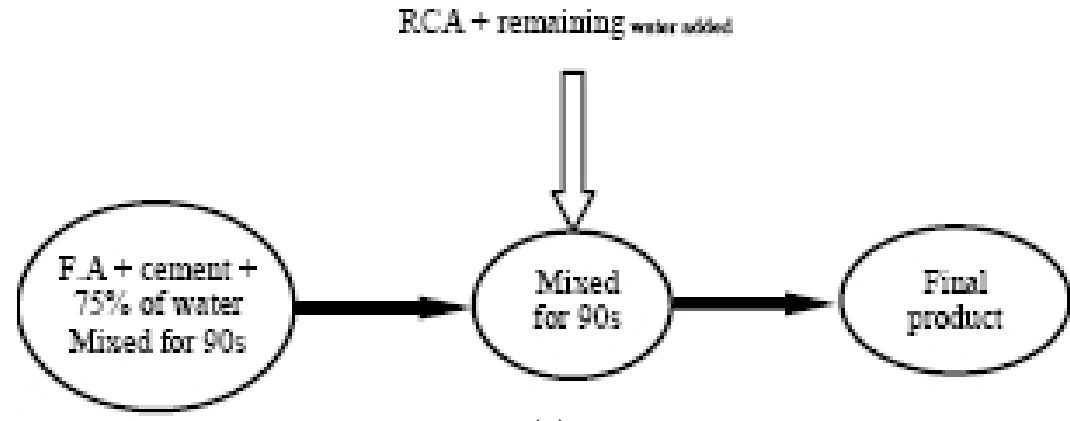

(a)

Full cement added RCA + remnining water added

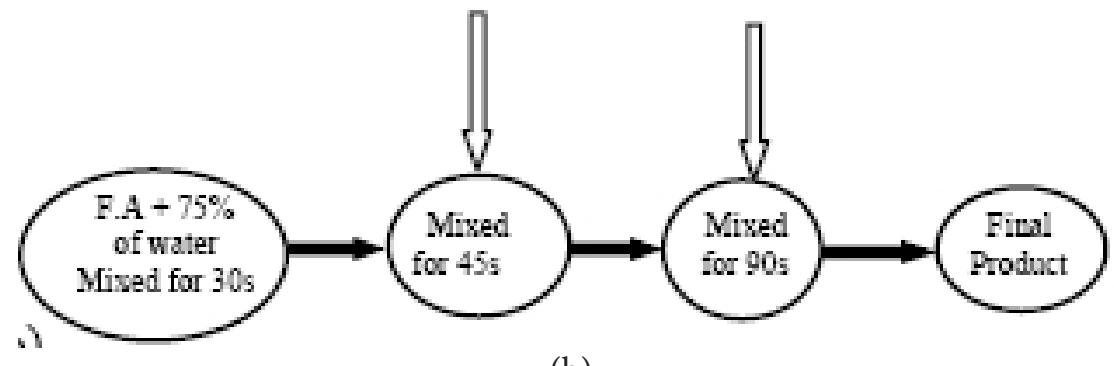

(b)

Figure 8. (a) Motar Mixing Approach11 (b) Sand Envaloped Mixing Approach11. 


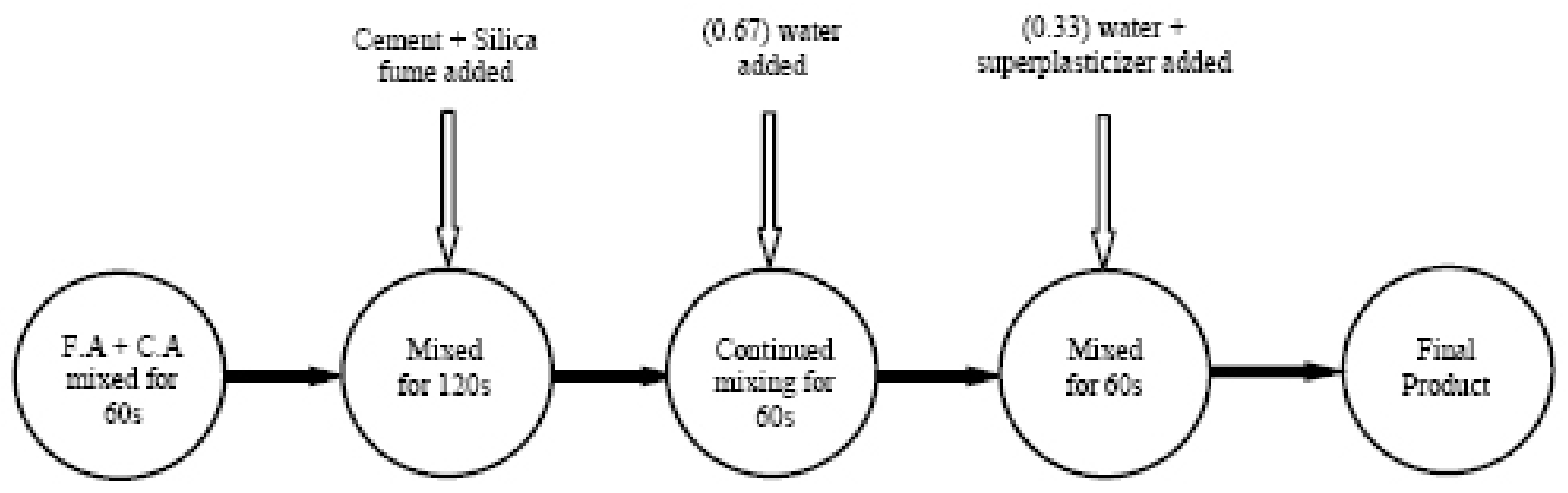

Figure 9. Mixing Approach $\frac{12}{}$.

\section{Conclusion}

From the literature review it was concluded that the properties of RAC is effected by Interfacial Transition Zones of RA, so to overcome this problem or make the ITZ stronger, different mixing approaches were adopted and it shown the comparable strength with normal concrete. Hence the concrete with suitable added fly ash and silica fume can be studied for better performance by adopting new mixing approach.

\section{References}

1. Otsuki N, Miyazato S, Yodsudjai W. Influence of recycled aggregate on interfacial transition zone, strength, chloride penetration and carbonation of concrete. Journal of Materials in Civil Engineering. 2003 Oct; 15(5):443-51.

2. Poon CS, Shui ZH, Lam L. Effect of microstructure of ITZ on compressive strength of concrete prepared with recycled aggregates. Construction and Building Materials. 2004 Mar; 18(6):461-8.

3. Tam VWY, Gao XF, Tam CM. Microstructural analysis of recycled aggregate concrete produced from two-stage mixing approach. Cement and Concrete Research. 2005 Oct; 35(6):1195-203.

4. Tam VWY, Gao XF, Tam CM. Comparing performance of modified two-stage mixing approach for producing recycled aggregate concrete. Magazine of Concrete Research. 2006 Sep; 58(7):477-84.

5. Tam VWY, Tam CM, Wang Y. Optimization on proportion for recycled aggregate in concrete using two-stage mixing approach. Construction and Building Materials. 2007 Sep; 21(10):1928-39.

6. Tam VWY, Tam CM. Diversifying Two-Stage Mixing Approach (TSMA) for recycled aggregate concrete: TSMAs and TSMAsc. Construction and Building Materials. 2008 Sep; 22(10):2068-77.

7. Li W, Xiao J, Sun Z, Shiho K, Surendra PS. Interfacial transition zones in recycled aggregate concrete with different mixing approaches. Construction and Building Materials. 2012 Jun; 35:1045-55.

8. Xiao J, Li W, Sun Z, David AL, Surendra PS. Properties of interfacial transition zones in recycled aggregate concrete tested by nanoindentation. Cement and Concrete Composites. 2013 Jan; 37:276-92.

9. Lee GC, Choi HB. Study on interfacial transition zone of recycled aggregates by micro-hardness test. Construction and Building Materials. 2013 Dec; 40:455-60.

10. Elhakam AA, Mohamed AE, Awad E. Influence of self-healing, mixing method and adding silica fume on mechanical properties of recycled aggregates concrete. Construction and Building Materials. 2012 May; 35:421-7.

11. Liang YC, Ye ZM, Vernerey F, Xi Y. Development of processing methods to improve strength of concrete with 100\% recycled coarse aggregate. Journal of Materials in Civil Engineering. 2013.

12. Dilbas H, Simsek M, Cakır O. An investigation on mechanical and physical properties of Recycled Aggregate Concrete (RAC) with and without silica fume. Construction and Building Materials. 2014 Mar; 61:50-9.

13. Utilisation of granite chips as a supplementary coarse aggregate material. 2016 Jan; 9(2). 